\title{
The girdles of the oldest fossil turtle, Proterochersis robusta, and the age of the turtle crown
}

Walter G Joyce ${ }^{1,2^{*}}$, Rainer R Schoch ${ }^{3}$ and Tyler R Lyson ${ }^{4}$

\begin{abstract}
Background: Proterochersis robusta from the Late Triassic (Middle Norian) of Germany is the oldest known fossil turtle (i.e. amniote with a fully formed turtle shell), but little is known about its anatomy. A newly prepared, historic specimen provides novel insights into the morphology of the girdles and vertebral column of this taxon and the opportunity to reassess its phylogenetic position.

Results: The anatomy of the pectoral girdle of $P$. robusta is similar to that of other primitive turtles, including the Late Triassic (Carnian) Proganochelys quenstedti, in having a vertically oriented scapula, a large coracoid foramen, a short acromion process, and bony ridges that connect the acromion process with the dorsal process, glenoid, and coracoid, and by being able to rotate along a vertical axis. The pelvic elements are expanded distally and suturally attached to the shell, but in contrast to modern pleurodiran turtles the pelvis is associated with the sacral ribs.

Conclusions: The primary homology of the character "sutured pelvis" is unproblematic between P. robusta and extant pleurodires. However, integration of all new observations into the most complete phylogenetic analysis that support the pleurodiran nature of $P$. robusta reveals that this taxon is more parsimoniously placed along the phylogenetic stem of crown Testudines. All current phylogenetic hypotheses therefore support the basal placement of this taxon, imply that the sutured pelvis of this taxon developed independently from that of pleurodires, and conclude that the age of the turtle crown is Middle Jurassic.
\end{abstract}

\section{Background}

Turtles are one of the most enigmatic groups of living vertebrates and many questions remain unanswered regarding the origin of the group and the age of the crown clade. Whereas much has recently been written on the origin of turtles [1-7] and significant progress has been made on the origin of their unique body plan [8-11], the debate is still ongoing regarding the age of the crown clade and the origin of the two main extant turtle lineages: pleurodires and cryptodires. For instance, a series of recent papers have explored whether the Early Jurassic turtle Kayentachelys aprix is best interpreted as the oldest known stem cryptodire [12,13] or a stem turtle [14-16]. However, these different interpretations imply a significantly different age of the turtle crown, which in return

\footnotetext{
* Correspondence: walter.joyce@unifr.ch

'Department of Geosciences, University of Tübingen, Hölderlinstr. 12, 72074

Tübingen, Germany

${ }^{2}$ Department of Geosciences, University of Fribourg, 1700 Fribourg,

Switzerland

Full list of author information is available at the end of the article
}

informs and/or conflicts with current molecular clock studies $[5,17-19]$.

The concurrent debate regarding the phylogenetic placement of the oldest known shelled amniote, Proterochersis robusta from the Late Triassic (Middle Norian) of Germany, is of equal importance. This taxon has traditionally been thought to have a pelvis that is sutured to the inside the shell (i.e., a "sutured pelvis") and to therefore be an early stem pleurodire, as this is traditionally believed to be an unambiguous apomorphy of the group $[12,20,21]$. However, others have argued that the sutured pelvis originated twice [22] or have even doubted the presence of this character in this taxon [14]. We here present a newly prepared specimen of $P$. robusta from the Late Triassic of Baden-Württemberg, Germany that not only exhibits all details of the pelvis, but also of the pectoral girdle and part of the vertebral column. The specimen is of particular importance because it helps clarify the orientation of the scapula among basal turtles, confirms the unambiguous presence of a sutured pelvis in $P$. robusta, and provides an abundance of other

\section{Biomed Central}

(c) 2013 Joyce et al.; licensee BioMed Central Ltd. This is an open access article distributed under the terms of the Creative Commons Attribution License (http://creativecommons.org/licenses/by/2.0), which permits unrestricted use, distribution, and reproduction in any medium, provided the original work is properly cited. 
character information that further corroborates its basal position of this taxon along the turtle stem lineage.

\section{Methods}

SMNS (Staatliches Museum für Naturkunde Stuttgart) 17757 was collected by a forest worker in 1933 between the villages of Klaffenbach and Althütte, about $40 \mathrm{~km}$ WNW of Stuttgart, Baden-Württemberg, Germany. The specimen was shortly thereafter acquired by the Royal Natural History Collection of Württemberg (the precursor of SMNS), but it appears to have been completely ignored by scientists and remained undescribed to date. Although the precise locality is not preserved, the fossil certainly originated from the Lower Stubensandstein, which falls within the basal part of the $\mathrm{k} 5$ sandstone unit of the Keuper (Löwenstein Formation) and corresponds to the Middle Norian (Alaunian), ca. 212-210 Ma [23]. All known specimens of $P$. robusta, including the holotype, were collected in the broader vicinity of SMNS 17757 (i.e., the region between the Murrhardt and Rems rivers) and from the same stratigraphic layers (pers. comm. Dieter Seegis), and the attribution of SMNS 17757 to $P$. robusta is unambiguously supported by the presence of a high-domed carapace, two pairs of abdominal scutes, and the morphology of the pelvis [20]. SMNS 17757 suffered extensive damage during recovery and most of the carapacial and plastral bones are missing, which is likely the primary reason why this specimen was ignored for so long. However, given that parts of the girdles and vertebral column were protruding from the remaining steinkern, preparation was initiated in recent years resulting in the exposure of the girdles and portions of the vertebral column associated with the shell. A series of photographs were taken by the preparator during preparation using a low-budget point and shoot camera that document the position at which various bones were found prior to their removal from the block (see Additional file 1: Figure S1).

The phylogenetic position of $P$. robusta has been resolved to be at the very base of the turtle lineage by multiple analyses in recent years [14,22,24-26], but opposition is fierce and some still favour placing this taxon at the base of the pleurodiran lineage $[12,27,28]$. To test the impact of the novel morphological insights provided by this study, we modified the analysis of Gaffney et al. [12], which is the most recent global analysis to advocate the pleurodiran affinities of this taxon. The following modifications were undertaken:

1) The Late Triassic proto-turtle Odontochelys semitestacea [29] was added to the matrix based on personal observations of the paratype (Institut for Vertebrate Paleontology and Paleoanthropology V13240) by WGJ and TRL.
2) The scoring of the Early Jurassic stem-turtle Kayentachelys aprix was modified following Joyce and Sterli [16]. All "problem characters" were scored derived (see [16]), thereby favouring the cryptodiran affinities proposed for this taxon [12].

3) The composite taxon "Megapleurodira" was split into the Late Jurassic stem-pleurodire Platychelys oberndorferi and crown group Pleurodira based on personal observations of the relevant material by WGJ and TRL. The scoring of crown Pleurodira differs from that of Megapleurodira in the scoring of seven characters: 65 (1, not $0 \& 1$, i.e., cervical vertebrae formed); 70 ( $1 \& 2$, not $0 \& 1 \& 2$, i.e., cervical vertebrae pro- or opisthocoelous); 76 (1\&2, not $0 \& 1 \& 2$, i.e., 8 th cervical procoelous or biconvex); 87 (1, not 0\&1, i.e., first thoracic reduced); 94 (2, not 1, i.e., supramarginals absent); 97 (1, not $0 \& 1$, i.e., plastral buttresses reach costals); 109 (0, not ?, i.e., pectoral scute does not overlap onto entoplastron).

4) The scoring of Proterochersis robusta was updated based on the new observations presented herein. In addition to replacing numerous missing scorings, the following corrections were undertaken for $P$. robusta: character 86 (?, not 1, we cannot replicate the meaning of this character and therefore score it as unknown); character 91 (?, not 1, i.e., it is unknown if the $10^{\text {th }}$ thoracic rib contributes to the sacrum); and 99 ( 1 or 2 , not 0 , i.e., the dorsal epiplastral processes does not contact the nuchal dorsally).

5) We added a character state to character 103 (i.e., $0=$ two pair of mesoplastra present, $1=$ one pair of mesoplastra present, 2 = mesoplastra absent). See Additional file 2 for complete character/taxon matrix. A maximum parsimony analyses was performed using PAUP 4.0b10 [30]. All characters were left unordered and unweighted, minimum branch length were set to collapse if branch lengths equalled zero, and the most parsimonious solution was sought using 1000 randomly seeded heuristic searches, thereby closely replicating the analysis of Gaffney et al. [12].

\section{Results}

\section{Pectoral girdle}

The dorsal process of the scapulacoracoid is elongate and striated distally (Figure 1). The acromial process is only half the length of the dorsal process, is slightly curved distally, and connected to the dorsal process, the glenoid, and the coracoid by bony ridges. The glenoid is fused, peanut-shaped, lacks a distinct neck, and consists of a flat facet formed by the coracoid and a flat facet formed by the scapula that are arranged at an angle of 120 degrees relative to one another (Figure 1B). The coracoid is a broad, flattened blade and a distinct coracoid 


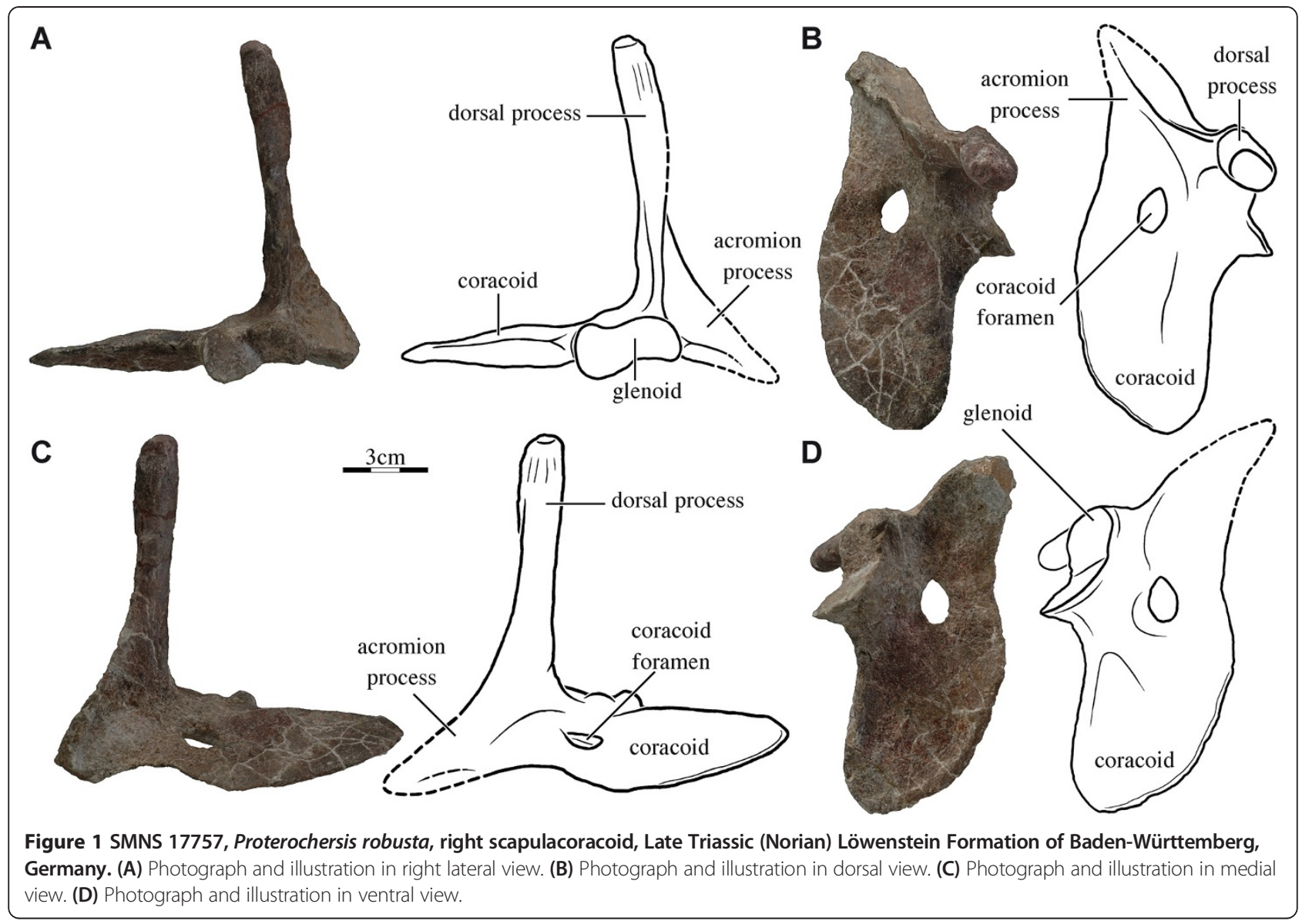

foramen is present. The right and left scapulacoracoids were removed from the block during preparation, but the scapular processes were oriented vertically (see Additional file 1: Figure S1A, C), the distal end of the acromion was only separated by a small gap from the plastron, and the coracoid blades were oriented horizontally essentially mirroring the condition seen in all extant turtles (see Additional file 1: Figure S1B).

\section{Pelvic girdle}

The elements of the pelvic girdle are fully fused with one another and it is therefore not possible to assess their relative contributions to the acetabulum (Figure 2A, B). The acetabulum is oriented laterally and has the outline of a rounded triangle.

The ilium has a short neck that expands distally to form a broad and rounded sutural contact with the carapace. However, in contrast to extant pleurodires, where the carapace received the ilium via a facet, the carapace is thickened at the articulation site to form a broad descending process (Figure 2A, B).

The right pubis is disarticulated from the plastron and it is therefore possible to study the articular process in detail. The pubis articulates with the plastron along a distally expanded, anteroposteriorly elongated process. The distal end of the pubis is rounded whereas a shallow depression is apparent on the plastron. The contact therefore appears to have been intermediate between the fully sutured condition seen in pleurodires and the loose articulation seen in cryptodires. The pubes are fused along the midline and form an expanded, ventrally curved, tongue-like epipubic process that is about as long as the remaining pubic body. The epipubic process is slightly discoloured relative to the main body of the pelvis, but it is unclear if it is calcified or ossified.

The exact nature of the ischial contact with the plastron is obscured by damage to the specimen, but it appears to have been more sutural than the pubic contact. The ischia contact the plastron along distally expanded processes that have a triangular cross-section, but it remains unclear if the ischia contact one another along the midline. A laminar piece of damaged bone is situated within the pelvic opening just posterior to the pubis. It is possible that this bone is a remnant of the ossified hypoischium, but too little is preserved to be confident in this identification (Figure 2B). 


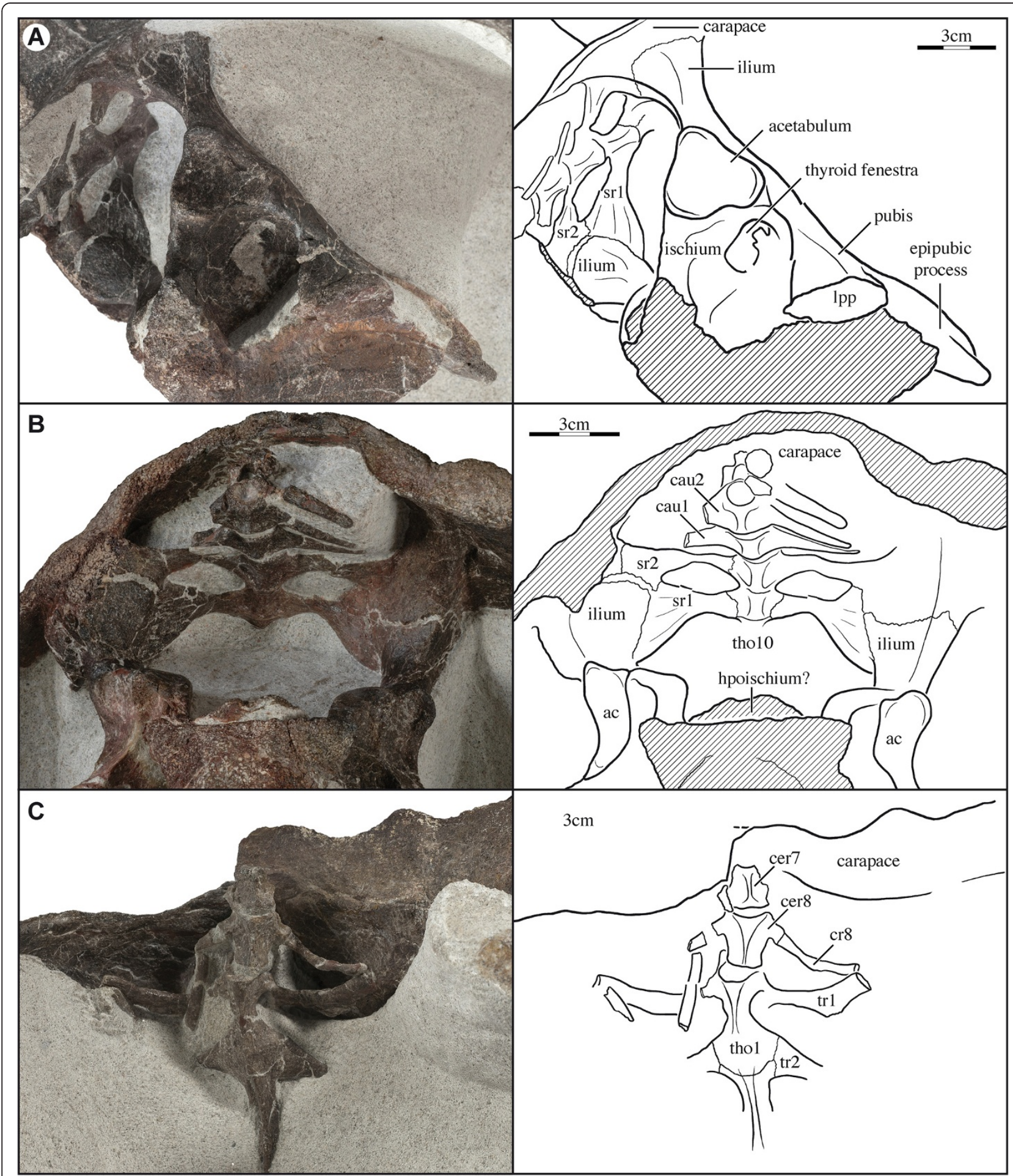

Figure 2 SMNS 17757, Proterochersis robusta, Late Triassic (Norian) Löwenstein Formation of Baden-Württemberg, Germany.

(A) Photograph and illustration of pelvic girdle in oblique right ventrolateral view. (B) Photograph and illustration of sacrum in oblique posteroventral view. (C) Photograph and illustration of posterior cervical column and anterior thoracic column in ventral view. Abbreviations: ac $=a c e t a b u l u m ;$

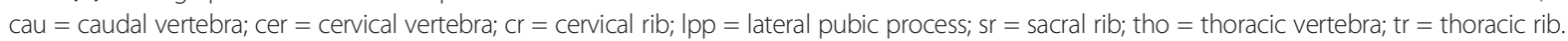
Shaded areas represent damaged bone surfaces. 


\section{Anterior plastral lobe}

The anterior margin of the anterior plastral lobe is heavily damaged, but some insights are nevertheless available. The posterior entoplastral process is highly distinct in visceral view and extends far beyond the level of the axillary notches (not illustrated). The base of the dorsal epiplastral process sensu [31,32] is preserved on both sides of the specimen, but careful analysis of the ventral side of the carapace reveals that the dorsal epiplastral process did not articulate with the nuchal bone dorsally (see Additional file 1: Figure S1), as in Proganochelys quenstedti [31] and, perhaps, Palaeochersis talampayensis [33].

\section{Anterior vertebral column}

The majority of bones that form the nuchal region of the shell are well preserved and show few signs of disarticulation (Figure 2C; Additional file 1: Figure S1C). The region consists of the posterior half of the seventh cervical vertebra, the entire eighth cervical vertebra, the first and second thoracic vertebrae, and the proximal portions of the eighth cervical rib and the first and second thoracic ribs.

The seventh cervical vertebra is only partially preserved and is strongly keeled ventrally. The eighth cervical vertebra is complete, but still partially embedded in matrix, and generally resembles those of other Triassic turtles [29,31,33]: it has a short centrum and a tall neural arch and dorsal process, is amphicoelous, the cervical ribs attach to a single transverse process that is located at the anterior third of the centrum, and a low keel decorates the ventral side of the centrum. There is no evidence of a formed articulation between the eighth cervical vertebra and the nuchal. The eighth cervical rib is damaged and its full length is therefore not apparent, but the portion that is preserved is about twice the anteroposterior length of the eighth cervical centrum. The eighth cervical rib has a single headed rib head and the body of the rib is round to oval in cross section for its entire preserved length. The eighth cervical rib was found in close alignment with the first thoracic rib posterior to the dorsal process of the scapulacoracoids (see Additional file 1: Figure S1).

The anterior central articulation of the first thoracic vertebra with the eighth cervical vertebra is oriented anteriorly, as in all basal turtles and pleurodires, and appears to be convex. The posterior articulation with the second thoracic vertebra is tight, but the suture is still apparent. The remaining thoracic vertebrae are still covered by sediment. Only the proximal portion of the first thoracic rib is preserved. It is a vertically oriented, recurved, flat element that articulates with the anterior end of the first thoracic vertebra proximally and has an elongate contact with the carapace dorsally. The vast majority of the distal portion of the first thoracic rib, however, appears to have been free, as seen in the few basal turtles that preserve this area (i.e., Proganochelys quenstedti [31] and Heckerochelys romani [34]). The second thoracic rib has an anteroposteriorly-broadened contact with the first and second thoracic vertebrae and is $\mathrm{T}$-shaped in cross section. The anterior two-thirds of this contact is with the first thoracic vertebra, whereas the remaining third is with the second thoracic vertebra. The first and second thoracic vertebrae are lightly keeled.

\section{Sacral region}

The sacral vertebrae and ribs are preserved in the posterior region of the specimen in addition to the posterior part of the last (tenth?) thoracic vertebra and large portions of the first to third caudal vertebrae (Figure 2B). The sacral vertebrae are tightly sutured to one another and with the last thoracic vertebra and lack a distinct ventral ridge. As in the majority of basal amniotes, the first sacral rib is significantly larger than the second [31]. The proximal end of the first sacral rib is anteroposteriorly expanded, much as the thoracic ribs are, but is unusual among turtles in that the anterior third of the rib contacts the last thoracic vertebra (only partially visible in Figure 2B). The first sacral rib is broadly expanded distally and suturally articulates with the ilium and with the second sacral rib. The proximal portion of the second sacral rib is also greatly expanded, but only has a small anterior contact with the first sacral vertebra (not visible in Figure 2). The left second sacral rib clearly articulates with the first sacral rib anteriorly and with the ilium distally, and appears to contact the carapace as well. The distal contact with the ilium is not apparent on the right side, but it is unclear if this is due to preservation. It is unclear if the thoracic ribs are involved in the formation of the sacrum, because the relevant area is covered by matrix, but the symplesiomorphic alignment of the ilium with the sacral ribs makes such a contact unlikely.

The two preserved caudal centra lack distinct ventral ridges. All caudals appear to be amphicoelous. The transverse processes of the first three caudal vertebrae are well developed and universally appear to be part of the vertebra, not separate ribs. The transverse processes have a broad base, are dorsoventrally flattened, and are slightly oriented to the anterior.

\section{Discussion}

\section{The orientation of the scapula in basal turtles}

The scapulacoracoid of extant turtles is a triradiate element consisting of the dorsal and acromion processes of the scapula and of the coracoid [31]. The dorsal process and the acromion process articulate dorsally and ventrally, respectively, along ligaments with the nuchal 
and the plastron and the scapulacoracoid can rotate along a vertical axis defined by these two flexible articulations. The entire shoulder girdle is therefore able to pivot along a vertical axis, allowing turtles to achieve greater stride length [35], a feature that is likely advantageous for any shelled organism.

The vertical orientation of the dorsal process in front of the ribcage was long believed to be a unique apomorphy of turtles, but a recent study demonstrates that this arrangement is universally found among basal amniotes [10]. Along those lines, a vertically oriented dorsal process is found in the potential stem turtle Eunotosaurus africanus [10], in the unambiguous stem turtle Odontochelys semitestacea [29], in the Late Triassic stem turtle Palaeochersis talampayensis [33], and can now be confirmed to be present in the oldest known turtle (i.e., amniotes with a fully developed turtle shell) Proterochersis robusta.

The scapulacoracoid of the Late Triassic Proganochelys quenstedti resembles that of Proterochersis robusta in all primary aspects, but has been described as having a dorsal process that is oriented obliquely towards the anterior [31]. The resulting, unusually shaped scapulacoracoid is difficult to fit inside the shell and cannot perform the rotating function seen in all other turtles as sometimes reconstructed [36] because it does not correctly articulate with the plastron. The vast majority of $P$. quenstedti specimens are plastically deformed and it is often difficult to assess the true shape of various bones. Among available specimens, the scapula is oriented anteriorly in some and vertically, as in P. robusta, in others [31]. However, the anterior orientation was favoured by Gaffney [31] in his final reconstruction of this taxon, because a single specimen, SMNS 16980, preserves this orientation on both sides of the skeleton and was therefore argued to be the least distorted. The observation that all newly described turtles that phylogenetically frame $P$. quenstedti have a vertically oriented scapula allows us to conclude that it is more likely that SMNS 16980 has symmetrically deformed scapulacoracoids and that the vertical orientation found in all other P. quenstedti specimens is the correct orientation for this taxon as well.

In addition to revealing that the scapular processes are oriented vertically in all basal turtles, the newly prepared specimen of $P$. robusta demonstrates that the acromion process was nearly in contact with the midline of the plastron (see Additional file 1: Figure S1). It is therefore apparent that the ability to rotate was well established in all Triassic turtles (i.e., amniotes with a fully developed turtle shell).

\section{The sutured pelvis of Proterochersis robusta}

The morphology of the pelvis of the two groups of extant turtles differs fundamentally. In all extant cryptodires, the distal ends of all pelvic elements are narrow and lack any sutural connection with the shell. By contrast, in all extant pleurodires the distal ends of all pelvic elements are greatly expanded and more or less firmly sutured to the carapace dorsally and with the plastron ventrally.

We herein confirm that the pelvic elements of Proterochersis robusta are distally expanded and sutured to the shell, despite initial doubt from the senior author [14]. However, a significant difference is nevertheless present between the morphology of the sutured pelvis of all known unambiguous total group pleurodires and that of $P$. robusta: the sacrum of $P$. robusta is formed by the sacral ribs, whereas the sacrum of all known total group pleurodires is formed by the posterior thoracic ribs [12]. Despite this substantial structural difference we conclude that the primary homology [37] of the sutured pelvis of $P$. robusta and pleurodires is unproblematic, because a transition from one state to the other is feasible. In particular, given that the pelvis is normally associated with the two sacral vertebrae, it is highly plausible that the suturing of the pelvis occurred while the association with these vertebrae was maintained. Once the pelvis was sutured to the shell and the sacral vertebrae lost their primary function, it is plausible that the pelvis shifted anteriorly relative to the ribs and only then became associated with the thoracic vertebrae, while loosing its connection with the sacral vertebrae. However, even if the primary homology of the sutured pelvis is unproblematic and P. robusta is linked to pleurodires by the presence of a sutured pelvis, only a parsimony analysis using the total evidence available from the skeleton is able to test the secondary homology of this character $[16,38,39]$.

\section{The phylogenetic placement of Proterochersis robusta and the age of the turtle crown}

Although all recent phylogenies of turtle relationships are in agreement that homoplasy is rampant $[12,14,25,26,28]$, some characters have proven to be less problematic and can be used to diagnose groups with confidence [19]. The sutured pelvis of Proterochersis robusta was already used in the type description to align this turtle with extant pleurodires [20], but numerous authors have since ignored the presence of the suture pelvis and preferred grouping P. robusta with other primitive turtles [40-42], likely because of the conspicuous presence of numerous primitive characters in this taxon, such as the presence of two pairs of mesoplastra, three pairs of inframarginal scutes, and an elongate posterior entoplastral process.

The cladistic revolution is the starting point for the modern debate. As all potential outgroups lack a sutured pelvis, Gaffney [21] concluded that the prolific presence of primitive characters in $P$. robusta is irrelevant and that this taxon should be grouped with extant pleurodires 
based on the shared derived presence of a sutured pelvis. However, this assessment was not tested rigorously for another 20 years until $P$. robusta was placed as a separate terminal taxon into a global matrix of turtle relationships. The first analysis do to so [22] arrived at the surprising conclusion that extant cryptodires and pleurodire share a number of derived characters that $P$. robusta lacks and that that taxon is therefore most parsimoniously interpreted as a stem turtle and the sutured pelvis a homoplasy. The majority of subsequent analyses agree on this interpretation [e.g., 14,22,24-26,34], but others still favour the pleurodiran affinities of this taxon $[12,27,43]$.

Our morphological analysis of the new $P$. robusta specimen reveals a number of additional characters that further corroborate the basal placement of $P$. robusta, as they are present in basal turtles, but absent in both cryptodires and pleurodires. These include the 1) presence of a coracoid foramen, 2) bony ridges that connect the acromion process with the dorsal process, glenoid, and coracoid, 3) a short acromion process, 4) cervical ribs, and 5) elongate first thoracic ribs. Addition of these characters to those phylogenetic hypotheses that already advocate the basal placement of $P$. robusta is certain to further cement the placement of this taxon along the phylogenetic stem of crown Testudines.

To test the impact of the morphology of the girdles and vertebral column on those analyses that previously preferred the pleurodiran affinities of P. robusta, we herein chose to update the most recent and most carefully constructed character/taxon matrix [12] that favours this hypothesis. The matrix was primarily updated to reflect novel insights into the morphology of $P$. robusta and $K$. aprix $[13,15,16]$ and by including the unambiguous proto-turtle Odontochelys semitestacea [29]. The parsimony analysis resulted in 30 most parsimonious trees (see Figure 3 for consensus cladogram) of 236 steps (consistency index excluding uninformative characters = 0.54 ; retention index $=0.74$ ). The tree topology generally resembles that of Gaffney et al. [12], but differs in that $K$. aprix and P. robusta are universally placed outside of crown Testudines in all most parsimonious trees. The updated matrix therefore supports the basal position of these two taxa, implies that the sutured pelvis seen in $P$. robusta and pleurodires evolved independently, and is consistent with a basal divergence of crown turtles in the Middle Jurassic [14,19,24,26].

\section{Conclusions}

Our study provides novel anatomical information for the oldest shelled turtle, which serves to help elucidate the numerous transformations necessary in the building of the unique turtle body plan. For example, the moderately robust shoulder girdle is intermediate in morphology between the more robust shoulder girdle found in

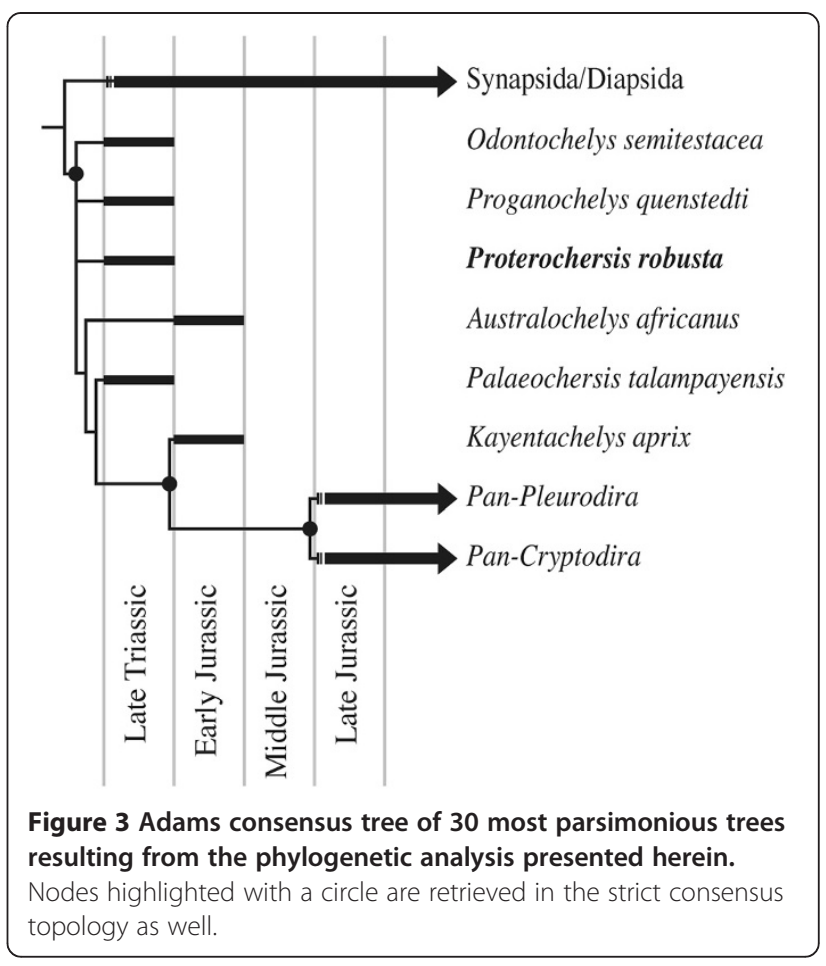

basal amniotes and basal diapsids and the much more gracile, triradiate structure found in later turtles. The well-preserved specimen of Proterochersis robusta confirms that the shoulder girdle was situated vertical and anterior to the ribcage (as in Odontochelys semitestacea), indicating a similar condition was likely present in the slightly plastically deformed Proganochelys quenstedti, which is the plesiomorphic condition. Our study highlights the importance of cladistics in determining homology between structures. The pelvis of $P$. robusta and total group pleurodires is sutured to the shell (albeit with some important differences), but when analysed in a phylogenetic analysis it is revealed that this feature is actually homoplastic. This implies that the age of crown turtles is younger than some studies suggest and that $P$. robusta should not be utilized as a calibration point for molecular calibration studies [19]. Finally, our study shows the importance of fossils in evolutionary biology by providing insights into the acquisition of the novel testudinate body plan.

\section{Additional files}

Additional file 1: Figure S1. SMNS 17757, Proterochersis robusta, Late Triassic (Norian) Löwenstein Formation of Baden-Württemberg, Germany. (A) Oblique anteroventral view of shell lying on its dorsal side with plastron removed documenting the original position of both scapulacoracoids. Note that the coracoid blades are both arranged along a horizontal plane. (B) Left lateral view of left acromion and plastron. Note that the acromion process (below) almost contacts the plastron ventrally (above). (C) Ventral view of posterior nuchal area prior to the removal of the scapulacoracoids (compare 
with Figure 2). The ventral portions of the scapulacoracoids are removed to provide a better view of the area. Note that the dorsal process of the scapula is positioned in front of the eighth cervical rib and first thoracic rib. Also note that an attachment site is lacking for a dorsal epiplastral process.

\section{Additional file 2: Character Taxon Matrix.}

\section{Competing interests}

The authors declare that they have no competing interests.

\section{Authors' contributions}

RRS initiated preparation of the specimen under study. WGJ documented specimen and performed phylogenetic analyses together with TRL. All authors helped interpret the data, draft the manuscript, and approved the final manuscript.

\section{Acknowledgements}

We thank V. Régent for careful preparation of the specimen used in this study and W. Gerber for help with photography. M. Matzke and M. Maisch are acknowledged for having helped initiate this study. A. Hsiang assisted with some of the phylogenetic analyses. D. Seegis provided important insights regarding the stratigraphy of Baden-Württemberg whereas J. Anquetin, M. Rabi, P. Romano, J. Sterli, J. Parham, and I. Werneburg helped improve the quality of this manuscript. The Open Access Fund of the University of Tübingen Library is thanked for funding the publication of this manuscript.

\section{Author details}

'Department of Geosciences, University of Tübingen, Hölderlinstr. 12, 72074 Tübingen, Germany. ${ }^{2}$ Department of Geosciences, University of Fribourg, 1700 Fribourg, Switzerland. ${ }^{3}$ Staatliches Museum für Naturkunde Stuttgart, 70191 Stuttgart, Germany. ${ }^{4}$ Department of Vertebrate Zoology, National Museum of Natural History, Smithsonian Institution, Washington DC, WA 20560 USA.

Received: 23 August 2013 Accepted: 26 November 2013 Published: 6 December 2013

\section{References}

1. Werneburg I, Sánchez-Villagra MR: Timing of organogenesis support basal position of turtles in the amniote tree of life. BMC Evol Biol 2009, 9:82.

2. Lyson TR, Bever GS, Bhullar B-AS, Joyce WG, Gauthier JA: Transitional fossils and the origin of turtles. Biol Lett 2010, 6:830-833.

3. Lyson TR, Sperling EA, Heimburg AM, Gauthier JA, King BL, Peterson KJ: microRNAs support a turtle + lizard clade. Biol Lett 2012, 8:104-107.

4. Crawford NG, Faircloth BC, McCormack JE, Brumfield RT, Winker K, Glenn TC: More than 1000 ultraconserved elements provide evidence that turtles are the sister group of archosaurs. Biol Lett 2012, 8:783-786.

5. Chiari Y, Cahais V, Galter N, Delsuc F: Phylogenomic analyses support the position of turtles as the sister group of birds and crocodiles (Archosauria). BMC Evol Biol 2012, 10:65.

6. Abramyan J, Badenhorst D, Biggar KK, Borchert GM, Botka CW, 36 Additional co-authors, et al: The Western painted turtle genome, a model for the evolution of extreme physiological adaptations in a slowly evolving lineage. Genome Biol 2013, 14:R28.

7. Wang Z, Pacual-Anaya J, Zadissa A, Li W, Niimura Y, 29 Additional coauthos, et al: The draft genomes of soft-shell turtle and green sea turtle yield insights into the development and evolution of the turtle-specific body plan. Nat Genet 2013, 45:701-706.

8. Nagashima H, Sugahara F, Takechi M, Ericsson R, Kawashima-Ohya Y, Narita $Y$, Kuratani S: Evolution of the turtle body plan by the folding and creation of new muscle connections. Science 2009, 325:193-196.

9. Kuratani S, Kuraku S, Nagashima H: Evolutionary developmental perspective for the origin of turtles: the folding theory for the shell based on the developmental nature of the carapacial ridge. Evol Dev 2011, 13:1-14

10. Lyson TR, Joyce WG: Evolution of the turtle bauplan: the topological relationship of the scapula relative to the ribcage. Biol Lett 2012 8:1028-1031.

11. Lyson TR, Bever GS, Scheyer TM, Hsiang AY, Gauthier JA: Evolutionary origin of the turtle shell. Curr Biol 2013, 23:1-7.
12. Gaffney ES, Rich TH, Vickers-Rich P, Constantine A, Vacca P, Kool L: Chubutemys, a new eucryptodiran turtle from the early cretaceous of Argentina, and the relationships of the Meiolaniidae. Am Mus Novitates 2007, 3599:1-35.

13. Gaffney ES, Jenkins FA: The cranial morphology of Kayentachelys, an early Jurassic cryptodire, and the early history of turtles. Act Zool 2010, 91:335-368.

14. Joyce WG: Phylogenetic relationships of Mesozoic turtles. Bull Peabody Mus Nat Hist 2007, 48:3-102.

15. Sterli J, Joyce WG: The cranial anatomy of the early Jurassic turtle Kayentachelys aprix. Act Palaeontol Pol 2007, 52:675-694.

16. Joyce WG, Sterli J: Congruence, non-homology, and the phylogeny of basal turtles. Act Zool 2012, 93:149-159.

17. Near TJ, Meylan PA, Shaffer HB: Assessing concordance of fossil calibration points in molecular clock studies: an example using turtles. Am Nat 2005, 165:137-146.

18. Lourenço JM, Claude J, Galtier N, Chiari Y: Dating cryptodiran nodes: origin and diversification of the turtle superfamily Testudinoidea. Mol Phyl Evol 2012, 62:496-507.

19. Joyce WG, Parham JF, Lyson TR, Warnock RCM, Donoghue PCJ: Fossil calibrations for molecular rate studies of turtle evolution: an example of best practice. J Paleontol 2013, 87:612-634.

20. Fraas E: Proterochersis, eine pleurodire Schildkröte aus dem Keuper. Jahrh Gesell Naturk Württemberg 1913, 69:13-90.

21. Gaffney ES: A phylogeny and classification of the higher categories of turtles. Bull Am Mus Nat Hist 1975, 155:389-436.

22. Rougier GW, de la Fuente MS, Arcucci AB: Late Triassic turtles from South America. Science 1995, 268:855-858

23. Menning M, Gast R, Hagdorn H, Käding HC, Simon T, Szurlies M, Nitsch E: Zeitskala für Perm und Trias in der Stratigraphischen Tabelle von Deutschland 2002, zyklostratigraphische Kalibrierung der höheren Dyas und Germanische Trias und das Alter der Stufen Roadium bis Rhaetium 2005. News/ Stratigr 2005, 41:173-210.

24. Danilov IG, Parham JF: A redescription of 'Plesiochelys' tatsuensis, a turtle from the late Jurassic of China, and its bearing on the antiquity of the crown clade cryptodira. J Vert Paleontol 2006, 26:573-580.

25. Sterli J, de la Fuente MS: A new turtle from the La Colonia formation (Campanian-Maastrichtian), Patagonia, Argentina, with remarks on the evolution of the vertebral column in turtles. Palaeontol 2011, 54:63-78.

26. Anquetin J: Reassessment of the phylogenetic interrelationships of basal turtles (Testudinata). I Syst Palaeontol 2012, 10:3-45.

27. Lapparent De Broin F, de Murelaga X: Turtles from Upper Cretaceous of Lano (Iberian Peninsula). Estud Mus Cienc Nat Alava 1999, 14:135-212.

28. Gaffney ES, Tong H, Meylan PA: Evolution of the side-necked turtles: the families Bothremydidae, Euraxemydidae, and Araripemydidae. Bull Am Mus Nat Hist 2006, 300:1-698.

29. Li C, Wu X-C, Rieppel O, Wang L-T, Zhao J: Ancestral turtle from the Late Triassic of Southwestern China. Nature 2009, 456:497-501.

30. Swofford DL: PAUP*: Phylogenetic Analysis Using Parsimony ( ${ }^{*}$ and Other Methods) [Computer Program]. Version 4. Sunderland: Sinauer Associates; 2003.

31. Gaffney ES: The comparative osteology of the Triassic turtle Proganochelys. Bull Am Mus Nat Hist 1990, 194:1-263.

32. Lyson TR, Bhullar B-AS, Bever GS, Joyce WG, de Queiroz K, Abzhanov A, Gauthier JA: Homology of the enigmatic nuchal bone reveals novel reorganization of the shoulder girdle in the evolution of the turtle shell. Evol Dev 2013, 15:317-325

33. Sterli J, de la Fuente MS, Rougier GW: Anatomy and relationships of Palaeochersis talampayensis, a Late Triassic turtle from Argentina. Palaeontogr A 2007, 281:1-61.

34. Sukhanov VB: An archaic turtle, Heckerochelys romani gen. et sp. nov., from the Middle Jurassic of Moscow region, Russia. Fossil Turtle Res 2006, 1(Russ J Herpetol Supple):112-118.

35. Walker WF: A structural and functional analysis of walking in the turtle, Chrysemys picta marginata. J Morphol 1971, 134:195-214.

36. Lee MSY: The homologies and early evolution of the shoulder girdle in turtles. Proc R Soc B 1996, 263:111-117.

37. de Pinna MGG: Concepts and tests of homology in the cladistic paradigm. Cladistics 1991, 7:367-394.

38. Nelson G, Platnik N: Systematics and Biogeography. New York: Columbia University Press; 1981.

39. Rieppel O: Fundamentals of Comparative Biology. Basel: Birkhauser Verlag; 1988

40. Romer AS: Osteology of the Reptiles. Chicago: University of Chicago Press; 1956. 
41. Kuhn O: Fossilium Catalogus, Vol. 1, Animalia, Part 107, Testudines. Gravenhage: Ysel Press; 1964

42. Mlynarski M: Handbuch der Paläoherpetologie. Part 7, Testudines. Stuttgart: Gustav Fischer Verlag; 1976

43. Hirayama R, Brinkman DB, Danilov IG: Distribution and biogeography of non-marine Cretaceous turtles. Russ J Herpetol 2000, 7:181-198.

doi:10.1186/1471-2148-13-266

Cite this article as: Joyce et al: The girdles of the oldest fossil turtle,

Proterochersis robusta, and the age of the turtle crown. BMC Evolutionary

Biology 2013 13:266.

\section{Submit your next manuscript to BioMed Central} and take full advantage of:

- Convenient online submission

- Thorough peer review

- No space constraints or color figure charges

- Immediate publication on acceptance

- Inclusion in PubMed, CAS, Scopus and Google Scholar

- Research which is freely available for redistribution 